\title{
"I never made it to the pros..." Return to sport and becoming an elite athlete after pediatric and adolescent anterior cruciate ligament injury-Current evidence and future directions
}

\author{
Eric Hamrin Senorski ${ }^{1}$ (1) $\cdot$ Romain Seil ${ }^{2}$ Eleonor Svantesson ${ }^{3}$. Julian A. Feller ${ }^{4}$ Kate E. Webster ${ }^{5}$. \\ Lars Engebretsen $^{6,7} \cdot$ Kurt Spindler $^{8} \cdot$ Rainer Siebold $^{9,10} \cdot$ Jón Karlsson $^{3,11} \cdot$ Kristian Samuelsson $^{3,11}$
}

Received: 16 August 2017 / Accepted: 20 November 2017 / Published online: 29 November 2017

(c) The Author(s) 2017. This article is an open access publication

\begin{abstract}
The management of anterior cruciate ligament (ACL) injuries in the skeletally immature and adolescent patient remains an area of controversy in sports medicine. This study, therefore, summarizes and discusses the current evidence related to treating pediatric and adolescent patients who sustain an ACL injury. The current literature identifies a trend towards ACL reconstruction as the preferred treatment option for ACL injuries in the young, largely justified by the risk of further structural damage to the knee joint. Worryingly, a second ACL injury is all too common in the younger population, where almost one in every three to four young patients who sustain an ACL injury and return to high-risk pivoting sport will go on to sustain another ACL injury. The clinical experience of these patients emphasizes the rarity of an athlete who makes it to elite level after a pediatric or adolescent ACL injury, with or without reconstruction. If these patients are unable to make it to an elite level of sport, treatment should possibly be modified to take account of the risks associated with returning to pivoting and strenuous sport. The surveillance of young athletes may be beneficial when it comes to reducing injuries. Further research is crucial to better understand specific risk factors in the young and to establish independent structures to allow for unbiased decision-making for a safe return to sport after ACL injury.
\end{abstract}

Level of evidence $\mathrm{V}$.

Keywords Anterior cruciate ligament $\cdot$ ACL $\cdot$ Pediatric $\cdot$ Adolescent $\cdot$ Return to sport $\cdot$ Sports $\cdot$ Reconstruction $\cdot$ Rehabilitation · PAMI

Eric Hamrin Senorski

eric.hamrin.senorski@gu.se

1 Department of Health and Rehabilitation, Institute of Neuroscience and Physiology, the Sahlgrenska Academy, University of Gothenburg, Gothenburg, Sweden

2 Sports Medicine Research Laboratory, Luxembourg Institute of Health, Strassen, Luxembourg

3 Department of Orthopaedics, Institute of Clinical Sciences, the Sahlgrenska Academy, University of Gothenburg, Gothenburg, Sweden

4 OrthoSport Victoria, Epworth HealthCare, Melbourne, VIC, Australia

5 School of Allied Health, La Trobe University, Melbourne, VIC, Australia
6 Oslo University Hospital and University of Oslo, Oslo, Norway

7 OSTRC, The Norwegian School of Sports Sciences, Oslo, Norway

8 Cleveland Clinic Sports Health Center, Garfield Heights, $\mathrm{OH}$, USA

9 Institute for Anatomy and Cell Biology, Ruprecht-Karls-University, Heidelberg, Germany

10 HKF, International Center for Hip, Knee, Foot Surgery and Sportstraumatology, ATOS Klinik, Heidelberg, Germany

11 Department of Orthopaedics, Sahlgrenska University Hospital, Mölndal, Gothenburg, Sweden 


\section{Introduction}

We all have that one friend who keeps telling everyone around us the story of how he never made it to the top and competed with the best in the world. What happened? A simple side-cut that went wrong during sports participation at 12 years of age. A twist of the knee and within milliseconds the devastating outcome of an anterior cruciate ligament (ACL) tear. At first, you may think how common it is to read about athletes returning to sport after this injury. Without accusing your friend of lying, you conclude that he probably gave up or re-considered life choices, graduated and started a great career in economics or sports injury research. Sadly, however, the story of not reaching the top in sports after a pediatric or adolescent ACL injury may be based more on fact than fiction. The clinical experience of these patients emphasizes the rarity of an athlete who makes it to elite level after a pediatric or adolescent ACL injury, with or without reconstruction. To our knowledge, there are no studies of this topic. Nevertheless, this raises the question of whether current treatment regimens and patient education need to be revised?

\section{History and current evidence}

An ACL tear is a common musculoskeletal injury, often sustained by athletes who participate in cutting and pivoting sports. A reconstruction of the ACL is often cited as the clinical standard to provide mechanical stability to the knee joint and a timely return to sport [1]. The available literature has shown that there is value to ACL reconstruction in patients after the age of 20 years [2-4]. However, there is limited literature about patients younger than 20 years of age.

Knee injuries have become more prevalent in children and adolescents over the last decade [5]. Studies based on reports from pediatric medical centers suggest that ACL injuries account for $6.3 \%$ of all sports injuries in children aged 5-12 and 10.6\% among adolescents aged 13-17 [6]. Historically, it has been reported that the rates of ACL reconstruction increase more than eight times in adolescents aged 15-18, compared with younger patients in the 11- to 14-year category [7]. The rates of ACL reconstructions in children and adolescents are now increasing at a significantly higher tempo than in the adult population $[7$, 8]. This is particularly reflected in the Australian population, where the number of ACL reconstructions in patients under 15 years of age has increased by a factor of four over the past 15 years [9]. This is a matter of concern, since the management of ACL injuries in the skeletally immature patient remains an area of controversy in sports medicine [10]. It should also be remembered that an ACL injury at a young age should be regarded as a lasting injury, regardless of the type of treatment [11].

The controversy can be partly explained by the fact that not all children and adolescents follow the average rates of skeletal growth. In general, the cessation of skeletal growth at the knee occurs at 14 years of age in girls and at 16 in boys. It is reported that, during the last few years of growth, the proximal tibial physis grows approximately $6 \mathrm{~mm}$ a year and the distal femoral physis contributes roughly $10 \mathrm{~mm}$ [12]. At the same time, knee laxity decreases, making the younger person's knee stiffer (Fig. 1) [13, 14]. In addition, there is large interindividual variability in the timing of the cessation of growth and this is due to discrepancies between chronological and skeletal age. This means that each patient should be analyzed carefully and individually [10]. In the presence of an

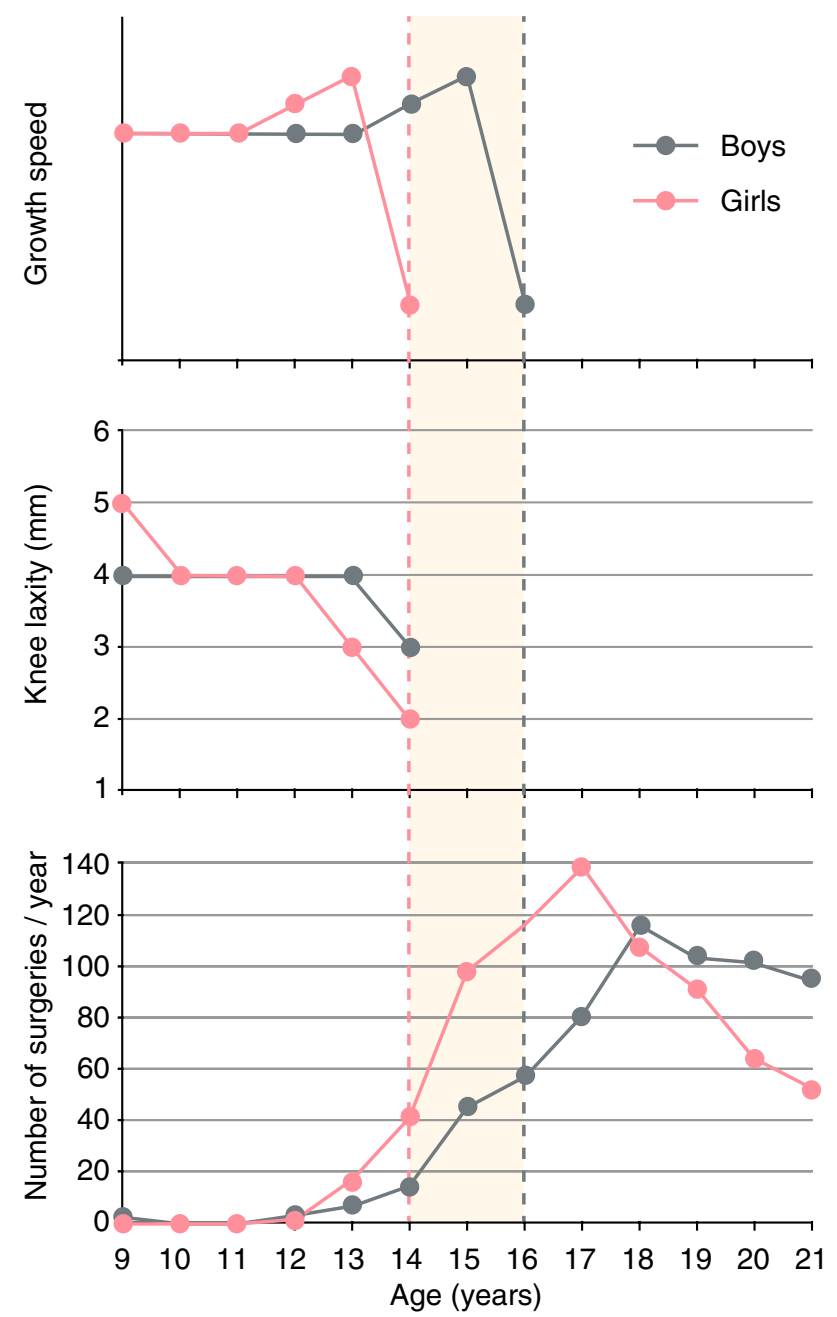

Fig. 1 Presentation of the relationship between age, growth speed and cessation, knee joint laxity, and average number of ACL surgeries performed 
open physis, treatment options for ACL injuries become contentious, due to the risk of surgical physeal insults, which may result in limb-length discrepancies or limb malalignment $[15,16]$. The anatomic placement of the graft during reconstructive procedures is also difficult due to the proximity of the growth plate to the aperture of the femoral tunnel [17].
Current options for treatment include non-surgical management with activity reduction or modification until physeal maturity, non-anatomic extra-articular procedures in which the graft is placed around the growth plate, physealsparing epiphyseal reconstruction where tunnels are placed within the tibial and femoral epiphysis, partial transphyseal procedures and transphyseal ACL reconstruction where

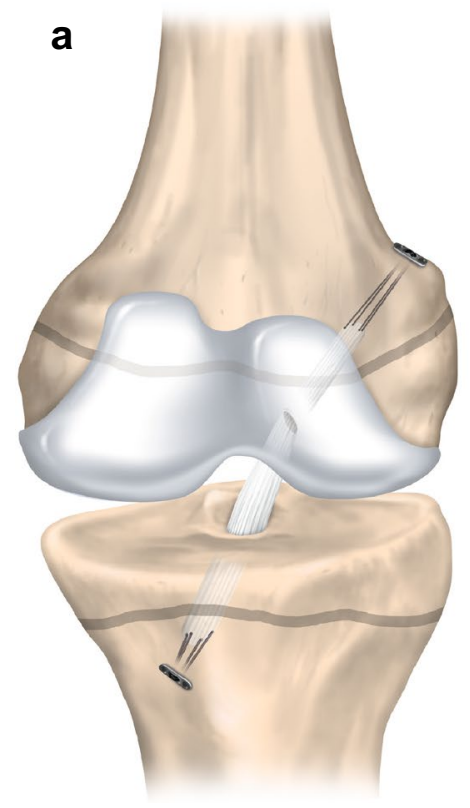

Transphyseal

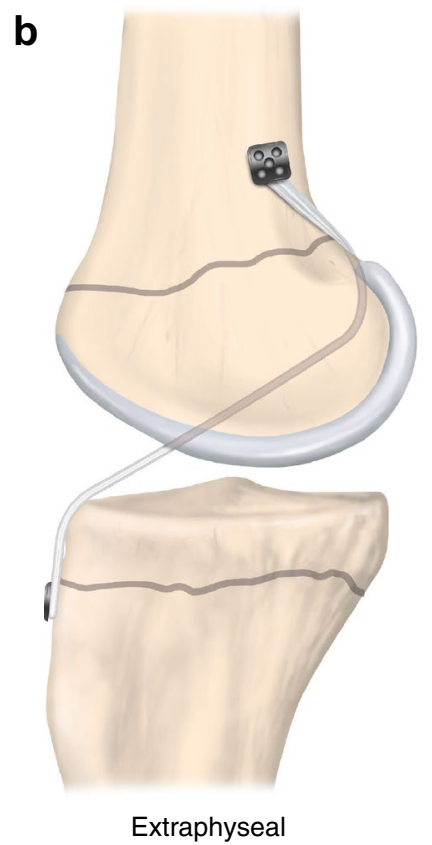

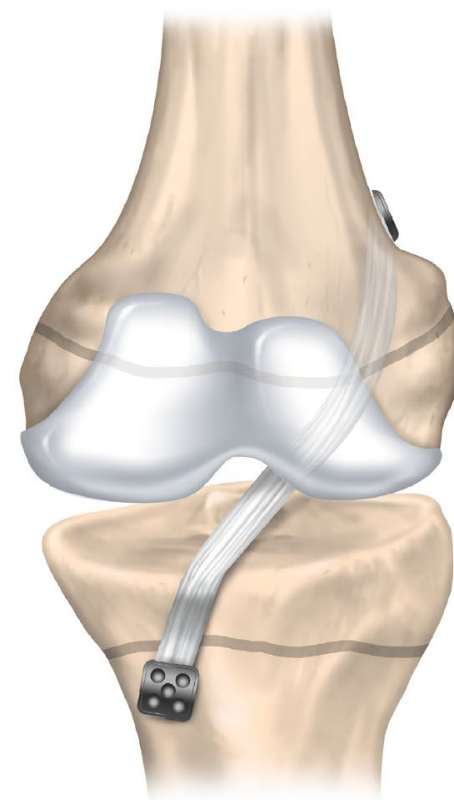

Extraphyseal

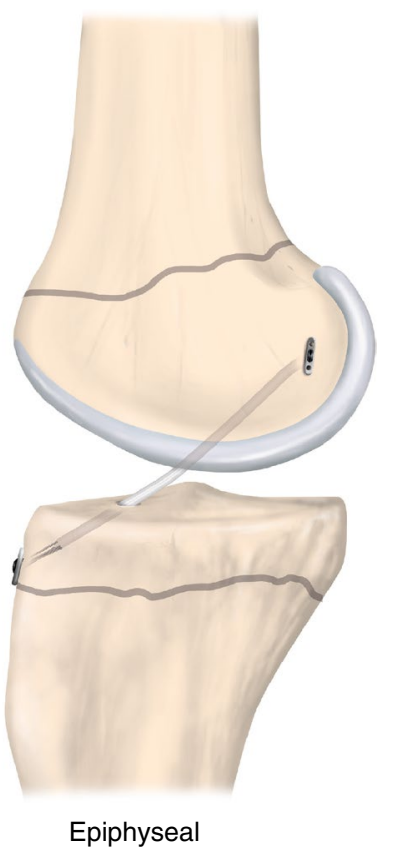

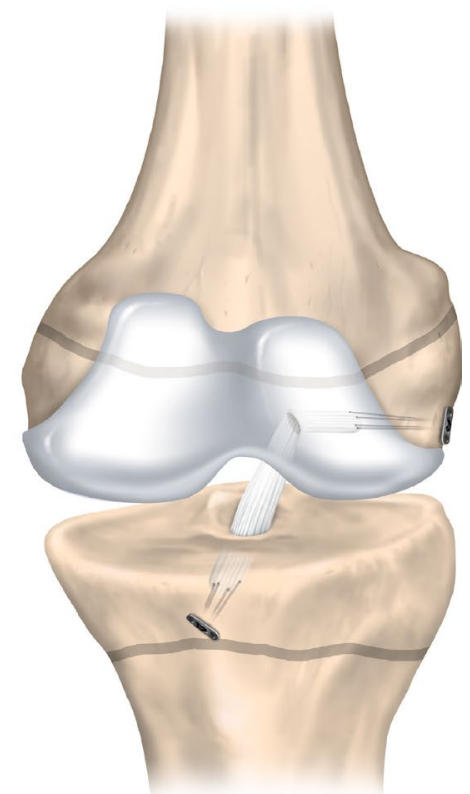

Epiphyseal
Fig. 2 Representation of different pediatric ACL reconstruction techniques in an anterior view (a) and lateral knee view (b). Surgeons differentiate between transphyseal and physeal-sparing techniques. The
ACL grafts are either placed within the epiphysis or turned around the physis. Many surgeons use different techniques on the femoral and the tibial side 
tunnels are drilled through the growth plates (Fig. 2) [15, 18, 19]. Each treatment option has potential complications. The growth-related complication rate has been evaluated at $<2 \%$ [15], but this may be underestimated [20]. An evidencebased approach would facilitate management decisions with respect to the delicate balance between the need to stabilize the patient's knee joint with reconstructive surgery and the requirement of avoiding complications due to physeal injuries [10]. ACL reconstruction in a skeletally immature patient is advocated to provide ligamentous knee-joint stability and potentially to protect the patient from subsequent concomitant injury. As with their adult counterparts, the absence of ligamentous knee-joint stability in children predisposes them to the risk of further meniscal and chondral injuries, thereby increasing the risk of early degenerative changes [21-23]. Additionally, the patient's desire to return to strenuous or pivoting sport is frequently described as an indication for surgical treatment, similar to that in patients over 20 years of age [24, 25].

The current literature identifies a trend towards ACL reconstruction as the preferred treatment option for ACL injuries in the young, largely justified by the risk of further structural damage to the knee joint but also by the challenges of ensuring the compliance of the young patient to modify his/her activity level and the sub-optimal outcomes associated with non-surgical treatment [26-28]. The overall literature supports a non-surgical approach initially in patients $<13$ years of age. As part of the non-surgical treatment, patients should be advised to modify their level of sports participation, refraining from pivoting sports $[10,19$, 20]. Regular clinical assessments may be supplemented by an MRI of the knee to rule out secondary meniscus or cartilage lesions [20, 29, 30]. The first prospective cohort study with a minimum of 2 years of follow-up in 52 pre-puberty children $(<12$ years) reported the appearance of secondary meniscal tears in $17 \%$ of ACL-injured patients [31]. This rate has to be contrasted to the high risk of second ACL injuries and other postoperative complications when it comes to surgical decision-making. Nonetheless, numerous surgical techniques and expert opinions on this topic have emerged [10]. This has been highlighted in a study by Moksnes et al. [20] who reported that there are substantial differences in preferred treatment algorithms and long-term follow-up procedures among orthopedic surgeons regarding the treatment of pediatric ACL injuries.

Typically, the surgical procedures involve a double autologous semitendinosus and gracilis graft of approximately $6-8 \mathrm{~mm}[15,32]$. Synthetic grafts and bone-patellar tendon-bone autografts should generally be avoided in the pediatric population because of the risk of growth disturbances [18, 33]. It is also recommended that drilling bone tunnels through a growth plate should be performed at a steep angle and a width of $<9 \mathrm{~mm}$, to minimize the cross-sectional area of the tunnels with the aim of reducing the risk of disturbing the epiphyseal plate $[10,16,19,20$, 34]. Additionally, the surgeon is able to confirm that tunnels are free of bone debris. It is also recommended that the pediatric patient who undergoes ACL reconstruction has annual standing long-leg radiographs to evaluate lower limb alignment and leg length discrepancy until skeletal maturity is reached at the level of the knee [29, 35].

The proportion of pediatric and adolescent patients who return to high-risk sports has been reported to be between 69 and 92\% [9, 36-38]. However, a lower proportion of these patients appear to return to their pre-injury sport. At the same time, if their age is considered, these patients may well be involved in several sports, making it difficult to determine what actually constitutes the pre-injury sport [38]. In addition to this, the level of sports practice is constantly evolving in this young population. In most pivoting sports, children and adolescents do not reach their highest level of sports participation until late adolescence or early adulthood. As a consequence, the concept of return to sports is more complex in this young population as compared to their adult counterparts. In a recent publication by Webster et al. [39], two-thirds of adolescent patients who sustained an ACL injury and were able to return to their sport reported that they were able to perform as well as before the injury. At a follow-up after an average of 5 years, $48 \%$ of female patients were still participating in pivoting sports, as were $54 \%$ of males. The same study also reported fear of a new injury or study/work commitments as the primary reasons for never returning to or dropping out of sport.

Nevertheless, there are no studies explicitly investigating present or future level of participation in top level or elite sport for pediatric and adolescent patients. Can such a patient return to sport safely and fulfill his/her dream of becoming an elite athlete in a pivoting sport? If not, treatment should possibly be modified to take account of the risks associated with returning to pivoting and strenuous sport.

Probably the most devastating complication following a return to sport is a second ACL injury, either a graft rupture or a contralateral ACL tear. Worryingly, a second ACL injury is all too common in the younger population (Fig. 3). In patients under 20 years of age, the probability of a second injury increases three to six fold [38]. Injury rates in younger cohorts have been reported to be as high as $30 \%$ in the literature [9, 38, 40, 41]. Aggregated results from reviews suggest that the younger patients who return to sports have a higher re-injury rate than those who do not $[25,42]$. The current evidence strongly indicates that the risk of a second ACL injury is greatest within the first 2 years after returning to pivoting sports $[9,38,43]$. Overall, almost one in every three to four young patients who sustain an ACL injury and return 
Fig. 3 Distribution of anterior cruciate ligament re-ruptures across age and patient sex
Total risk zones for rerupture

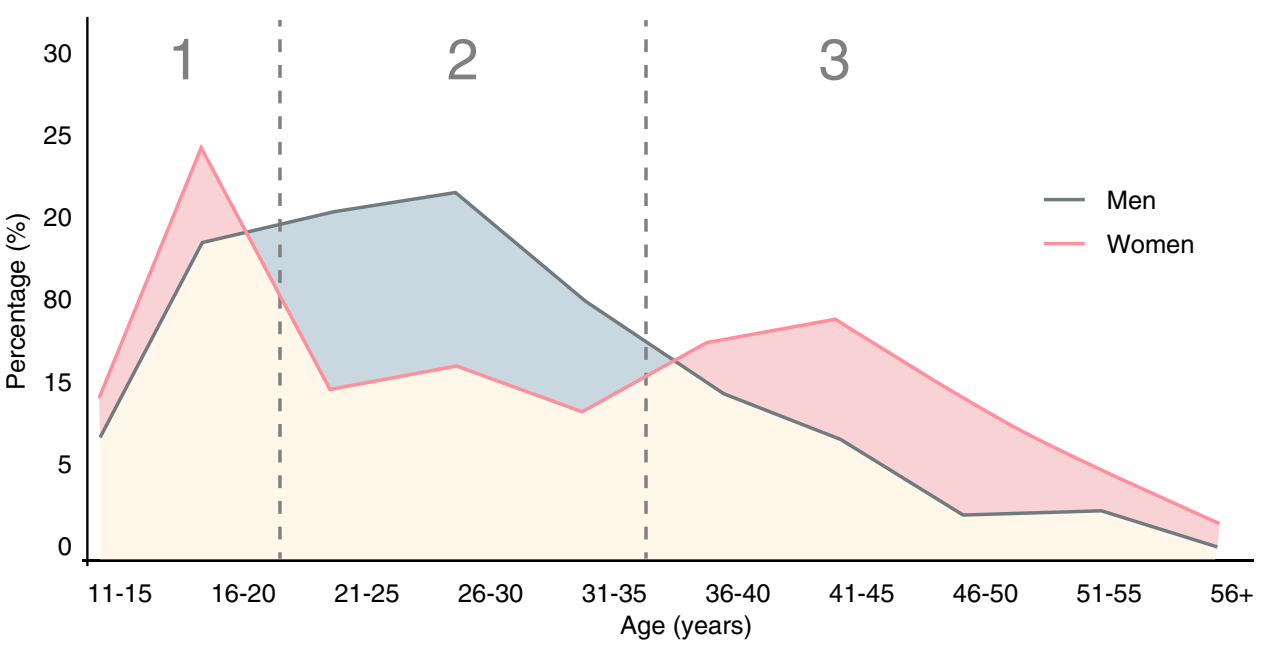

to high-risk pivoting sport will go on to sustain another ACL injury [38].

Compared with an uninjured counterpart, it has been suggested that a young patient who returns to sport after ACL reconstruction runs a 30-40 times greater risk of ACL injury [42]. A report from the Norwegian National Knee Ligament Register confirms that age is a significant risk factor for both revision and contralateral ACL reconstruction with hazard ratios of 4.0 and 4.9, respectively, for the 15- to 19-year age group, compared with patients over 30 years of age [44]. Additionally, publications from the Swedish ACL Registry have reported that adolescent patients 13-19 years of age have the highest rates of early revision and that this group runs an almost three times greater risk of contralateral ACL reconstruction $[2,45]$. These data suggest that the modification of sports participation, improved rehabilitation, the use of integrative neuromuscular training and validated criteria for a return to sport are important in the management of these patients to help them safely reintegrate into sport and reduce the risk of a second injury [46-49].

Interestingly, the literature suggests that the young active population appears to recover more quickly and transition back to sports earlier after ACL reconstruction compared with their older counterparts $[6,42,50]$. Nevertheless, a number of the younger patients have been reported to have remaining functional deficits and altered motor patterns [51, 52] in the reconstructed knee at the time of return to sport [53]. The current treatment approach of early accelerated rehabilitation and the expected timeframe of recovery of 9-12 months is potentially deleterious to younger athletes, as they may not be fully recovered [54]. Several authors have, therefore, suggested that waiting at least 2 years to reintegrate into high-risk sports will significantly benefit patients after ACL injury [9, 25, 55]. It must, however, be stressed that a prolonged waiting time for a return to sport may potentially further jeopardize these patients' ability and willingness to return to the same level of sport after missing at least two seasons. In other words, this may have serious consequences for the young athlete's immediate and future career.

Is it time to re-think the current treatment options for pediatric and adolescent patients with an ACL injury? Are we giving young patients, their parents and their coaches unrealistic expectations of returning to sport and the opportunity to become elite athletes? The literature tells us that most young patients are able to return to pivoting sport, but this is accompanied by the risk of a second ACL injury. Whether it is actually possible to become a world-class athlete after an ACL injury at a young age is a question that remains to be answered.

\section{Future directions}

In the past decade, there have been changes in terms of the surgical techniques used for ACL reconstruction and postoperative rehabilitation, as well as significant advances in the identification of risk factors for graft rupture and contralateral ACL injury in younger patients [56]. It is important that these advances in management are translated into clinical practice. However, the recent literature and clinical experience have not shown any reduction in secondary ACL injury risk or improved outcome after treatment [42].

The recovery of baseline knee health and function should be the fundamental prerequisite, if possible, prior to a return to sport following ACL injury, independent of patient age. Modifications to return to sport guidelines have the potential to reduce the re-injury risk and hopefully improve future sports performance in the young athlete after ACL injury. Although various return-to-sport guidelines exist, there is 
still no consensus about, or validation of, these guidelines. This means that return to sport decisions are often based on a combination of time since surgery and personal experience $[25,50,55,56]$.

While studies that focus on pediatric and adolescent populations who return to their previous sport and report on the level of participation are rare, registry data involving large numbers of patients are beginning to emerge [2, 43, 57]. It is worrying that many young patients have high expectations in terms of future sports performance, but it is likely that only the occasional patient will have a future in elite sport. There is an urgent future need for more detailed data on return to sport for the high-risk younger population.

It is possible that there is some natural selection in play that puts some individuals at a higher risk of initial rupture and subsequent re-rupture. Intrinsic risk factors, including morphological variants such as a higher degree of laxity among certain patients [14], exist. However, we are currently unable to identify with any certainty the individual athlete at risk. The surveillance of youth athletes has previously been used in an attempt to identify risk factors for ACL and overload injuries in young athletes. Several general factors related to training and competition load have been identified and are helping us to understand the injury panorama among the young (Table 1) [58-62]. For instance, Malisoux et al. [61] showed that an increase in weekly training intensity was associated with an increased risk of injury in younger athletes, similar to what is found in their older counterparts [63]. This suggests that monitoring young athletes may be beneficial when it comes to reducing, and potentially preventing, injuries. One good example of an initiative of this kind is the European Society of Sports Traumatology, Knee Surgery and Arthroscopy (ESSKA) that launched the ESSKA Pediatric Anterior Cruciate Ligament Monitoring Initiative (PAMI) [20]. The goal of this initiative is to serve as a multinational network of centers dealing with this clinical problem to share knowledge, increase awareness and improve the understanding of injury occurrence, treatment approaches, the long-term effects, anatomy, biomechanics and reconstruction in the pediatric population. The ultimate aim of the initiative is to create an international pediatric ACL registry.

This type of further research is crucial to obtain a better understanding of specific risk factors in the young and

Table 1 Risk indicators for anterior cruciate ligament injuries and other overload injuries identified from surveilling youth athletes

$>10$ days without rest

$>50 \%$ intense training sessions

Competition despite injury

$>7$ days indication of injury / symptom

Recurrent injuries to establish independent structures to allow for unbiased decision-making for a safe return to sport after ACL injury. There is also a lack of information on these patients' future quality of life and premature osteoarthritis development that needs to be addressed.

\section{Compliance with ethical standards}

Conflict of interest Two of the authors has declared the following potential conflict of interest or source of funding: Author KSpi receives funding from the National Institute of Arthritis and Musculoskeletal and Skin Diseases of the National Institutes of Health, DonJoy, and Smith \& Nephew. Author RS is the current president of ESSKA.

Funding No fundings were received for this study.

Open Access This article is distributed under the terms of the Creative Commons Attribution 4.0 International License (http://creativecommons.org/licenses/by/4.0/), which permits unrestricted use, distribution, and reproduction in any medium, provided you give appropriate credit to the original author(s) and the source, provide a link to the Creative Commons license, and indicate if changes were made.

\section{References}

1. Mall NA, Chalmers PN, Moric M, Tanaka MJ, Cole BJ, Bach BR Jr, Paletta GA Jr (2014) Incidence and trends of anterior cruciate ligament reconstruction in the United States. Am J Sports Med 42(10):2363-2370

2. Andernord D, Desai N, Bjornsson H, Ylander M, Karlsson J, Samuelsson K (2015) Patient predictors of early revision surgery after anterior cruciate ligament reconstruction: a cohort study of 16,930 patients with 2-year follow-up. Am J Sports Med 43(1):121-127

3. Desai N, Bjornsson H, Samuelsson K, Karlsson J, Forssblad M (2014) Outcomes after ACL reconstruction with focus on older patients: results from The Swedish National Anterior Cruciate Ligament Register. Knee Surg Sports Traumatol Arthrosc 22(2):379-386

4. Legnani C, Terzaghi C, Borgo E, Ventura A (2011) Management of anterior cruciate ligament rupture in patients aged 40 years and older. J Orthop Traumatol 12(4):177-184

5. Shea KG, Grimm NL, Ewing CK, Aoki SK (2011) Youth sports anterior cruciate ligament and knee injury epidemiology: who is getting injured? In what sports? When? Clin Sports Med 30(4):691-706

6. Stracciolini A, Casciano R, Levey Friedman H, Meehan WP 3rd, Micheli LJ (2013) Pediatric sports injuries: an age comparison of children versus adolescents. Am J Sports Med 41(8):1922-1929

7. Dodwell ER, Lamont LE, Green DW, Pan TJ, Marx RG, Lyman S (2014) 20 years of pediatric anterior cruciate ligament reconstruction in New York State. Am J Sports Med 42(3):675-680

8. Werner BC, Yang S, Looney AM, Gwathmey FW Jr (2016) Trends in pediatric and adolescent anterior cruciate ligament injury and reconstruction. J Pediatr Orthop 36(5):447-452

9. Morgan MD, Salmon LJ, Waller A, Roe JP, Pinczewski LA (2016) Fifteen-year survival of endoscopic anterior cruciate ligament reconstruction in patients aged 18 years and younger. Am J Sports Med 44(2):384-392 
10. Peterson DC, Ayeni OR (2016) Pediatric anterior cruciate ligament reconstruction outcomes. Curr Rev Musculoskelet Med 9(4):339-347

11. Ardern CL, Khan KM (2016) The old knee in the young athlete: knowns and unknowns in the return to play conversation. Br J Sports Med 50(9):505-506

12. Morrissy RT, Weinstein SL (2006) Lovell and Winter's pediatric orthopaedics. 6th edn. Lippincott Williams \& Wilkins, [2006] (C)2006, Philadelphia

13. Baxter MP (1988) Assessment of normal pediatric knee ligament laxity using the genucom. J Pediatr Orthop 8(5):546-550

14. Mouton C, Theisen D, Meyer T, Agostinis H, Nuhrenborger C, Pape D, Seil R (2015) Noninjured knees of patients with noncontact ACL injuries display higher average anterior and internal rotational knee laxity compared with healthy knees of a noninjured population. Am J Sports Med 43(8):1918-1923

15. Frosch KH, Stengel D, Brodhun T, Stietencron I, Holsten D, Jung C, Reister D, Voigt C, Niemeyer P, Maier M, Hertel P, Jagodzinski M, Lill H (2010) Outcomes and risks of operative treatment of rupture of the anterior cruciate ligament in children and adolescents. Arthroscopy 26(11):1539-1550

16. Seil R, Weitz FK, Pape D (2015) Surgical-experimental principles of anterior cruciate ligament (ACL) reconstruction with open growth plates. J Exp Orthop 2(1):11

17. McCarthy MM, Tucker S, Nguyen JT, Green DW, Imhauser CW, Cordasco FA (2013) Contact stress and kinematic analysis of all-epiphyseal and over-the-top pediatric reconstruction techniques for the anterior cruciate ligament. Am J Sports Med 41(6):1330-1339

18. Kaeding CC, Aros B, Pedroza A, Pifel E, Amendola A, Andrish JT, Dunn WR, Marx RG, McCarty EC, Parker RD, Wright RW, Spindler KP (2011) Allograft versus autograft anterior cruciate ligament reconstruction: predictors of failure from a MOON prospective longitudinal cohort. Sports Health 3(1):73-81

19. Mohtadi N, Grant J (2006) Managing anterior cruciate ligament deficiency in the skeletally immature individual: a systematic review of the literature. Clin J Sport Med 16(6):457-464

20. Moksnes H, Engebretsen L, Seil R (2016) The ESSKA paediatric anterior cruciate ligament monitoring initiative. Knee Surg Sports Traumatol Arthrosc 24(3):680-687

21. Anderson AF, Anderson CN (2015) Correlation of meniscal and articular cartilage injuries in children and adolescents with timing of anterior cruciate ligament reconstruction. Am J Sports Med 43(2):275-281

22. Lawrence JT, Argawal N, Ganley TJ (2011) Degeneration of the knee joint in skeletally immature patients with a diagnosis of an anterior cruciate ligament tear: is there harm in delay of treatment? Am J Sports Med 39(12):2582-2587

23. Newman JT, Carry PM, Terhune EB, Spruiell MD, Heare A, Mayo M, Vidal AF (2015) Factors predictive of concomitant injuries among children and adolescents undergoing anterior cruciate ligament surgery. Am J Sports Med 43(2):282-288

24. Grindem H, Eitzen I, Engebretsen L, Snyder-Mackler L, Risberg MA (2014) Nonsurgical or surgical treatment of ACL injuries: knee function, sports participation, and knee reinjury: the Delaware-Oslo ACL Cohort Study. J Bone Jt Surg Am 96(15):1233-1241

25. Webster KE, Feller JA (2016) Exploring the high reinjury rate in younger patients undergoing anterior cruciate ligament reconstruction. Am J Sports Med 44(11):2827-2832

26. Fabricant PD, Jones KJ, Delos D, Cordasco FA, Marx RG, Pearle AD, Warren RF, Green DW (2013) Reconstruction of the anterior cruciate ligament in the skeletally immature athlete: a review of current concepts: AAOS exhibit selection. J Bone Jt Surg Am 95(5):e28
27. Gausden EB, Calcei JG, Fabricant PD, Green DW (2015) Surgical options for anterior cruciate ligament reconstruction in the young child. Curr Opin Pediatr 27(1):82-91

28. Ramski DE, Kanj WW, Franklin CC, Baldwin KD, Ganley TJ (2014) Anterior cruciate ligament tears in children and adolescents: a meta-analysis of nonoperative versus operative treatment. Am J Sports Med 42(11):2769-2776

29. Engebretsen L, Steffen K, Bahr R, Broderick C, Dvorak J, Janarv PM, Johnson A, Leglise M, Mamisch TC, McKay D, Micheli L, Schamasch P, Singh GD, Stafford DE, Steen H (2010) The International Olympic Committee Consensus statement on age determination in high-level young athletes. Br J Sports Med 44(7):476-484

30. Yoo WJ, Kocher MS, Micheli LJ (2011) Growth plate disturbance after transphyseal reconstruction of the anterior cruciate ligament in skeletally immature adolescent patients: an MR imaging study. J Pediatr Orthop 31(6):691-696

31. Moksnes H, Engebretsen L, Eitzen I, Risberg MA (2013) Functional outcomes following a non-operative treatment algorithm for anterior cruciate ligament injuries in skeletally immature children 12 years and younger. A prospective cohort with 2 years followup. Br J Sports Med 47(8):488-494

32. Lemaitre G, Salle de Chou E, Pineau V, Rochcongar G, Delforge S, Bronfen C, Haumont T, Hulet C (2014) ACL reconstruction in children: a transphyseal technique. Orthop Traumatol Surg Res 100(4 Suppl):S261-S265

33. Hettrich CM, Dunn WR, Reinke EK, Spindler KP (2013) The rate of subsequent surgery and predictors after anterior cruciate ligament reconstruction: 2- and 6-year follow-up results from a multicenter cohort. Am J Sports Med 41(7):1534-1540

34. Seil R, Pape D, Kohn D (2008) The risk of growth changes during transphyseal drilling in sheep with open physes. Arthroscopy 24(7):824-833

35. Sled EA, Sheehy LM, Felson DT, Costigan PA, Lam M, Cooke TD (2011) Reliability of lower limb alignment measures using an established landmark-based method with a customized computer software program. Rheumatol Int 31(1):71-77

36. Mascarenhas R, Tranovich MJ, Kropf EJ, Fu FH, Harner CD (2012) Bone-patellar tendon-bone autograft versus hamstring autograft anterior cruciate ligament reconstruction in the young athlete: a retrospective matched analysis with 2-10 year follow-up. Knee Surg Sports Traumatol Arthrosc 20(8):1520-1527

37. Shelbourne KD, Gray T, Haro M (2009) Incidence of subsequent injury to either knee within 5 years after anterior cruciate ligament reconstruction with patellar tendon autograft. Am J Sports Med 37(2):246-251

38. Webster KE, Feller JA, Leigh WB, Richmond AK (2014) Younger patients are at increased risk for graft rupture and contralateral injury after anterior cruciate ligament reconstruction. Am J Sports Med 42(3):641-647

39. Webster KE, Feller JA, Whitehead TS, Myer GD, Merory PB (2017) Return to sport in the younger patient with anterior cruciate ligament reconstruction. Orthop J Sports Med 5(4):2325967117703399

40. Allen MM, Pareek A, Krych AJ, Hewett TE, Levy BA, Stuart MJ, Dahm DL (2016) Are female soccer players at an increased risk of second anterior cruciate ligament injury compared with their athletic peers? Am J Sports Med 44(10):2492-2498

41. Paterno MV, Rauh MJ, Schmitt LC, Ford KR, Hewett TE (2014) Incidence of second ACL injuries 2 years after primary ACL reconstruction and return to sport. Am J Sports Med 42(7):1567-1573

42. Wiggins AJ, Grandhi RK, Schneider DK, Stanfield D, Webster KE, Myer GD (2016) Risk of secondary injury in younger athletes 
after anterior cruciate ligament reconstruction: a systematic review and meta-analysis. Am J Sports Med 44(7):1861-1876

43. Lind M, Menhert F, Pedersen AB (2012) Incidence and outcome after revision anterior cruciate ligament reconstruction: results from the Danish registry for knee ligament reconstructions. Am J Sports Med 40(7):1551-1557

44. Persson A, Fjeldsgaard K, Gjertsen JE, Kjellsen AB, Engebretsen L, Hole RM, Fevang JM (2014) Increased risk of revision with hamstring tendon grafts compared with patellar tendon grafts after anterior cruciate ligament reconstruction: a study of 12,643 patients from the Norwegian Cruciate Ligament Registry, 20042012. Am J Sports Med 42(2):285-291

45. Andernord D, Desai N, Bjornsson H, Gillen S, Karlsson J, Samuelsson K (2015) Predictors of contralateral anterior cruciate ligament reconstruction: a cohort study of 9061 patients with 5-year follow-up. Am J Sports Med 43(2):295-302

46. Gokeler A, Bisschop M, Myer GD, Benjaminse A, Dijkstra PU, van Keeken HG, van Raay JJAM., Burgerhof JGM, Otten E (2016) Immersive virtual reality improves movement patterns in patients after ACL reconstruction: implications for enhanced criteriabased return-to-sport rehabilitation. Knee Surg Sports Traumatol Arthrosc 24(7):2280-2286

47. Hildebrandt C, Muller L, Zisch B, Huber R, Fink C, Raschner C (2015) Functional assessments for decision-making regarding return to sports following ACL reconstruction. Part I: development of a new test battery. Knee Surg Sports Traumatol Arthrosc 23(5):1273-1281

48. Sousa PL, Krych AJ, Cates RA, Levy BA, Stuart MJ, Dahm DL (2017) Return to sport: does excellent 6-month strength and function following ACL reconstruction predict midterm outcomes? Knee Surg Sports Traumatol Arthrosc 25(5):1356-1363

49. Walden M, Atroshi I, Magnusson H, Wagner P, Hagglund M (2012) Prevention of acute knee injuries in adolescent female football players: cluster randomised controlled trial. BMJ 344:e3042

50. Myer GD, Paterno MV, Ford KR, Quatman CE, Hewett TE (2006) Rehabilitation after anterior cruciate ligament reconstruction: criteria-based progression through the return-to-sport phase. J Orthop Sports Phys Ther 36(6):385-402

51. Paterno MV, Schmitt LC, Ford KR, Rauh MJ, Myer GD, Huang B, Hewett TE (2010) Biomechanical measures during landing and postural stability predict second anterior cruciate ligament injury after anterior cruciate ligament reconstruction and return to sport. Am J Sports Med 38(10):1968-1978
52. Webster KE, Feller JA (2012) Tibial rotation in anterior cruciate ligament reconstructed knees during single limb hop and drop landings. Clin Biomech (Bristol Avon) 27(5):475-479

53. Schmitt LC, Paterno MV, Hewett TE (2012) The impact of quadriceps femoris strength asymmetry on functional performance at return to sport following anterior cruciate ligament reconstruction. J Orthop Sports Phys Ther 42(9):750-759

54. Grindem H, Snyder-Mackler L, Moksnes H, Engebretsen L, Risberg MA (2016) Simple decision rules can reduce reinjury risk by $84 \%$ after ACL reconstruction: the Delaware-Oslo ACL cohort study. Br J Sports Med 50(13):804-808

55. Nagelli CV, Hewett TE (2017) Should return to sport be delayed until 2 years after anterior cruciate ligament reconstruction? Biological and functional considerations. Sports Med 47(2):221-232

56. Moksnes H, Grindem H (2016) Prevention and rehabilitation of paediatric anterior cruciate ligament injuries. Knee Surg Sports Traumatol Arthrosc 24(3):730-736

57. Johnsen MB, Guddal MH, Smastuen MC, Moksnes H, Engebretsen L, Storheim K, Zwart JA (2016) Sport participation and the risk of anterior cruciate ligament reconstruction in adolescents: a population-based prospective cohort study (The Young-HUNT Study). Am J Sports Med 44(11):2917-2924

58. Frisch A, Croisier JL, Urhausen A, Seil R, Theisen D (2009) Injuries, risk factors and prevention initiatives in youth sport. Br Med Bull 92:95-121

59. Frisch A, Seil R, Urhausen A, Croisier JL, Lair ML, Theisen D (2009) Analysis of sex-specific injury patterns and risk factors in young high-level athletes. Scand J Med Sci Sports 19(6):834-841

60. Frisch A, Urhausen A, Seil R, Croisier JL, Windal T, Theisen D (2011) Association between preseason functional tests and injuries in youth football: a prospective follow-up. Scand J Med Sci Sports 21(6):e468-e476

61. Malisoux L, Frisch A, Urhausen A, Seil R, Theisen D (2013) Monitoring of sport participation and injury risk in young athletes. J Sci Med Sport 16(6):504-508

62. Theisen D, Frisch A, Malisoux L, Urhausen A, Croisier JL, Seil R (2013) Injury risk is different in team and individual youth sport. J Sci Med Sport 16(3):200-204

63. Windt J, Zumbo BD, Sporer B, MacDonald K, Gabbett TJ (2017) Why do workload spikes cause injuries, and which athletes are at higher risk? Mediators and moderators in workload-injury investigations. Br J Sports Med 51(13):993-994 